\title{
Minimal access surgery
}

\author{
Tom Treasure
}

Minimal access coronary surgery offers the patient two potential advantages, to be spared the damaging effects of cardiopulmonary bypass, and a large and painful incision. Furthermore, it offers those who have to foot the bill the promise of a cheaper operation and a shorter hospital stay. Put like that, one might feel compelled to join the bandwagon for fear of being left behind as it gathers speed. But you would not be alone in hesitation. Bruce Lytle of the Cleveland Clinic, a surgeon who combines enormous experience with modesty and wisdom, began his recent editorial on minimal access surgery with a quote from Bruce Springsteen, “The door's open but the ride it ain't free." Ullyot titled his commentary on the avoidance of bypass for coronary surgery, "Look Ma, No Hands!" engaging snatches of colloquial American in the leading journals of cardiothoracic surgery, both advising caution, give us pause for thought.

What are we being asked to consider? The avoidance of cardiopulmonary bypass and a change in the incision are different questions. These two issues are packaged in the appealing phrase "minimal access" but they must be unpacked to examine the contents.

The coronary operation can be done: through a median sternotomy but without cardiopulmonary bypass ${ }^{3-6}$; with a limited incision but with femoro-femoral cardiopulmonary bypass $^{7}$; or with avoidance of both..$^{8-14}$

\section{Avoiding bypass}

A proponent of near conventional coronary surgery through a median sternotomy but without bypass is the Brazilian surgeon, Buffolo. $^{36}$ When he reported his first 593 cases $^{3}$ I was impressed by the extraordinarily low blood usage, only 8 units in the whole series. If the need for transfusion can be almost completely eliminated, it is likely that other systems also function better..$^{15}$ An accompanying editorial comment took a less positive tone and suggested that not using bypass might be to the detriment of the coronary anastomoses. ${ }^{16}$ Buffolo returned to print this year with a series of 1274 coronary operation done without bypass, $14.5 \%$ of all their cases, ${ }^{6}$ only to be cautioned in the "Look Ma, No Hands!" editorial. ${ }^{2}$

The patients in whom these techniques are applicable are likely to be those who need only a short time on bypass. Pfister ${ }^{4}$ compared 220 patients operated on without bypass with 220 retrospectively identified patients matched for the number of grafts, date of operation, and other factors. The mean cardiopulmonary bypass time in the matched cases was only 32 minutes. Note that it is a short period of bypass that is being avoided. In addition, it is bypass as practised in the 1990s that we should have in mind. It is unreasonable to imply that the damage they are being spared is akin to that in the landmark study of the damaging effects of cardiopulmonary bypass based on operations performed in $1981 .{ }^{17}$ The time related effect of bypass became evident after 90 minutes of bypass, and the paper includes data on cases with more than 120 minutes of bypass time. Steve Westaby has recently provided an authoritative review of the arguments for and against avoiding bypass for coronary artery surgery. ${ }^{18} \mathrm{He}$ argues that we may have overemphasised the damaging effects of cardiopulmonary bypass, but the work he cites was published 10 years ago ${ }^{17} 19$ and was appropriate to its time and context. He is absolutely right that the damaging effects of cardiopulmonary bypass should not be exaggerated in the present debate. The work done by a generation of researchers (including Westaby and ourselves) has been successful in making bypass safer. In arguing the case for avoidance of bypass as an advantage, it must be emphasised that it is only a short period of modern, low risk bypass that is saved.

\section{Choice of incision}

The minimal access wound may be a vertical parasternal incision ${ }^{7112}$ or a transverse anterior thoracotomy. ${ }^{8101314}$ All the advocates of a vertical incision, and some of those who make a transverse incision, resect the fourth costal cartilage, and often divide or resect the third cartilage as well. ${ }^{7111314}$ Some use a thoracoscope to aid internal mammary artery dissection. ${ }^{714}$ What they all have in common is limited access. Only a suitably positioned left anterior descending coronary artery and some diagonal branches can be grafted through this approach. ${ }^{10}$ Calafiore extends the left internal mammary artery with a length of inferior epigastric artery in some cases to get more length or to bridge from the left internal mammary

\footnotetext{
Blackshaw Road, London SW17 0QT Correspondence to: Professor T Treasure. Accepted for publication 3 January 1997
} 
artery to a diagonal. ${ }^{10}$ Cooley has added a right internal mammary graft ${ }^{13}$ and Angelini et $a l^{20}$ have added planned angioplasty to other vessels to supplement the revascularisation.

As far as the incision is concerned, the assumption we are invited to make is that median sternotomy is a major source of problems. For the majority, median sternotomy is a very satisfactory incision in which no muscles are cut. If the operation is short, and the sternum is spread sparingly and gently, patients tolerate sternotomy, they heal well and mobilise quickly. Thoracotomy, in its various applications is not necessarily a lesser trauma. In thoracic surgery we avoid resection of a costal cartilage in diagnostic and staging median sternotomy because it has been a source of trouble. Without resection of cartilage, the space is small. The intercostal incision is near the articulation with the sternum and spreading is only achieved by buckling a rib. The assumption that the shorter the skin incision the less the pain merits at least a tentative challenge. That sort of assumption fuelled a lot of the pressure for abdominal surgeons to take up laparoscopic cholecystectomy. A blind prospective randomised trial was at last performed comparing minimally invasive and open techniques. ${ }^{21}$ It has shown that time in hospital, return to full mobility, and return to work were the same for the two groups. In particular, it is interesting to reflect on the use of shortness of stay as a measure of outcome. In the cholecystectomy trial the patients (not knowing what sort of incisions lay under their dressings) went home when they felt ready, so that it could be used as a measure of outcome. ${ }^{21}$ Under most circumstances, patients go home when the surgeon decides, making it worse than useless as an independent measure of outcome in comparing one operation with another.

The minimal access approach has at least shattered one myth. It has been taught that you must divide the first intercostal branch when dissecting down the mammary artery. The notion was that the blood knows no better than to turn left at the first branch it comes to, and will not adequately perfuse the left anterior descending. I suspected that red cells, like most other things, take the path of least resistance. What matters is a good anastomosis, good run off with the resultant high velocity, and stimulation of endothelial derived growth factor, to ensure that, in time, the mammary artery delivers all the flow that is needed. Evidently, division of the first intercostal, which is not possible with most of the techniques described, is not as crucial as had been claimed.

We, like others, do the occasional case without bypass. My own view is that this corner is hardly worth cutting for a straightforward case with one or two vessels to be grafted. On the contrary, if the single vessel disease patient needs surgery, whether because of symptoms or prognosis (as may be argued with a proximal left anterior descending lesion), you had better get that single anastomosis right or the whole procedure is wasted. Where I think it is worth being aware of these technical options is with serious co-morbidity ${ }^{13}$ or in reoperations. ${ }^{5}$ There are occasions when we would like to "sneak" a graft onto a completely blocked dominant right coronary artery, or an important left sided vessel. From time to time it is useful to know some options for doing this without having to mobilise the whole heart or add the problems of cannulation and bypass. ${ }^{22}$

\section{A trial is needed}

As far as more routine practice is concerned, there seems to be only one sensible approach - to do a trial. Which cases can be considered? The majority of surgical patients have three vessel disease. Is there a subset of these who we would randomise for partial revascularisation through minimal access, or to have a planned sequence of minimal access surgery and angioplasty? ${ }^{20}$ If so, two surgical cohorts can be compared. Alternatively, we could look at patients with less severe disease who are not considered surgical candidates at present but are recommended to have angioplasty for left anterior descending disease. It is not too soon to do a trial because the number of publications indicate that several groups have already used this technique, although in several instances the experience is small. If we delay too long, some will argue that it is too late because the practice is established, the benefits are obvious, the patients are asking for it, their cardiologists expect it, it is cheaper, they are sent for that operation, and it would even be unethical to randomise. All of these arguments have been used in the debate about cholecystectomy but the self evident benefits were largely illusory. ${ }^{21}$ In coronary revascularisation we have a good track record for performing trials. ${ }^{2324}$ In the case of minimal access coronary surgery, there is a multicentre trial asking to be done. Can it be done?

1 Lytle BW. Minimally invasive cardiac surgery. 7 Thorac Cardiovasc Surg 1996;111:554-5.

2 Ullyot DJ. Look Ma, No Hands! Ann Thorac Surg 1996; 61:10-11.

3 Buffolo E, Andrade JCS, Branco JNR, Aguiar LF, Ribeiro $\mathrm{EE}$, Jatene $\mathrm{AD}$. Myocardial revascularization without extracorporeal circulation. Eur $\mathcal{f}$ Cardiothorac Surg 1990;4:504-7.

4 Pfister AJ, Zaki S, Garcia JM, Mispireta LA, Corso PJ, Qazi AG, et al. Coronary artery bypass without cardiopulmonary bypass. Ann Thorac Surg 1992;54:1085-92.

5 Fanning WJ, Kakos GS, Williams TE. Reoperative coronary artery bypass grafting without cardiopulmonary bypass. Ann Thorac Surg 1993;55:486-9.

6 Buffolo E, de Andrade JCS, Branco JNR, Teles CA, Aguiar LF, Gomes WJ. Coronary artery bypass grafting withou cardiopulmonary bypass. Ann Thorac Surg 1996;61:63-6.

7 Robinson MC, Gross DR, Zeman W, Stedje-Larsen E. Minimally invasive coronary artery bypass grafting: a new Minimally invasive coronary artery bypass grafting: a new 1995;10:529-36.

8 Benetti FJ, Ballester C, Sani G, Doonstra P, Grandjean J. Video assisted coronary bypass surgery. $\mathcal{f}$ Cardiac Surg 1995;10:620-5.

9 Calafiore AM, Angelini GD. Left anterior small thoracotomy (LAST) for coronary revascularisation [letter].

10 Calafiore AM, Di Giammarco G, Teodori G, Bosco G, D'Annunzio E, Barsotti A, et al. Left anterior descending coronary artery grafting via left anterior small thoracotomy without cardiog

11 Stanbridge RDeL, Symons GV, Banwell PE. Minimalaccess surgery for coronary artery revascularisation. access surgery for
Lancet $1995 ; 346: 837$. 
12 Stanbridge RDeL, Cohen A, Hadjinicolau L, Al-Katoubi A. Early experience with minimal invasive coronary artery bypass grafting [abstract]. Heart 1996;75(Suppl 1):P69.

13 Cooley DA. Limited access myocardial revascularization. Tex Heart Inst $\mathcal{f}$ 1996;23:81-4.

14 Acuff TE, Landreneau RJ, Griffith BP, Mack MJ Minimally invasive coronary artery bypass grafting. Ann Thorac Surg 1996;61:135-7.

15 Treasure T. Discussion of reference 3. Eur $\mathcal{f}$ Cardiothorac Surg 1990;4:507.

16 Messmer BJ. Coronary surgery without extracoporeal circulation: benefit or extra risk for the patient? Eur $\mathcal{F}$ Cardiothorac Surg 1990;4.509.

17 Kirklin JK, Westaby S, Blackstone EH, Kirklin JW, Chenoweth $\mathrm{DE}$, Pacifico $\mathrm{AD}$. Complement and the damaging effects of cardiopulmonary bypass. $\mathcal{F}$ Thorac damaging effects of cardiopulm.

18 Westaby W. Coronary surgery without cardiopulmonary bypass. Br Heart f 1995;73:203-5.

9 Smith PCL, Treasure T, Newman SP, Joseph P, Ell PJ, Schneidau A, et al. Cerebral consequences of cardiopulmonary bypass. Lancet 1986 ; i:823-5.

20 Angelini GD, Wilde P, Salerno TA, Calafiore AM Integrated left small thoractomy and angioplasty for multivessel coronary artery revascularisation. Lancet 1996; 347:757-8.

21 Majeed AW, Troy G, Nicholl JP, Smythe A, Reed MWR Stoddard CJ, et al. Randomised, prospective, single-blind comparison of laparascopic versus small-incision cholecystectomy. Lancet 1996;347:989-94.

22 Westaby S, Benetti FJ. Less invasive coronary surgery: consensus from the Oxford meeting. Ann Thorac Surg 1996, 62:924-31.

23 Kumar P, Treasure T. Coronary artery bypass graft trials. Brf Hosp Med 1996;56:33-6.

24 Horton R. Surgical research or comic opera: questions, but few answers. Lancet 1996;347:984-5.

\section{IMAGES IN CARDIOLOGY}

\section{Aneurysm of the left coronary artery bifurcation}

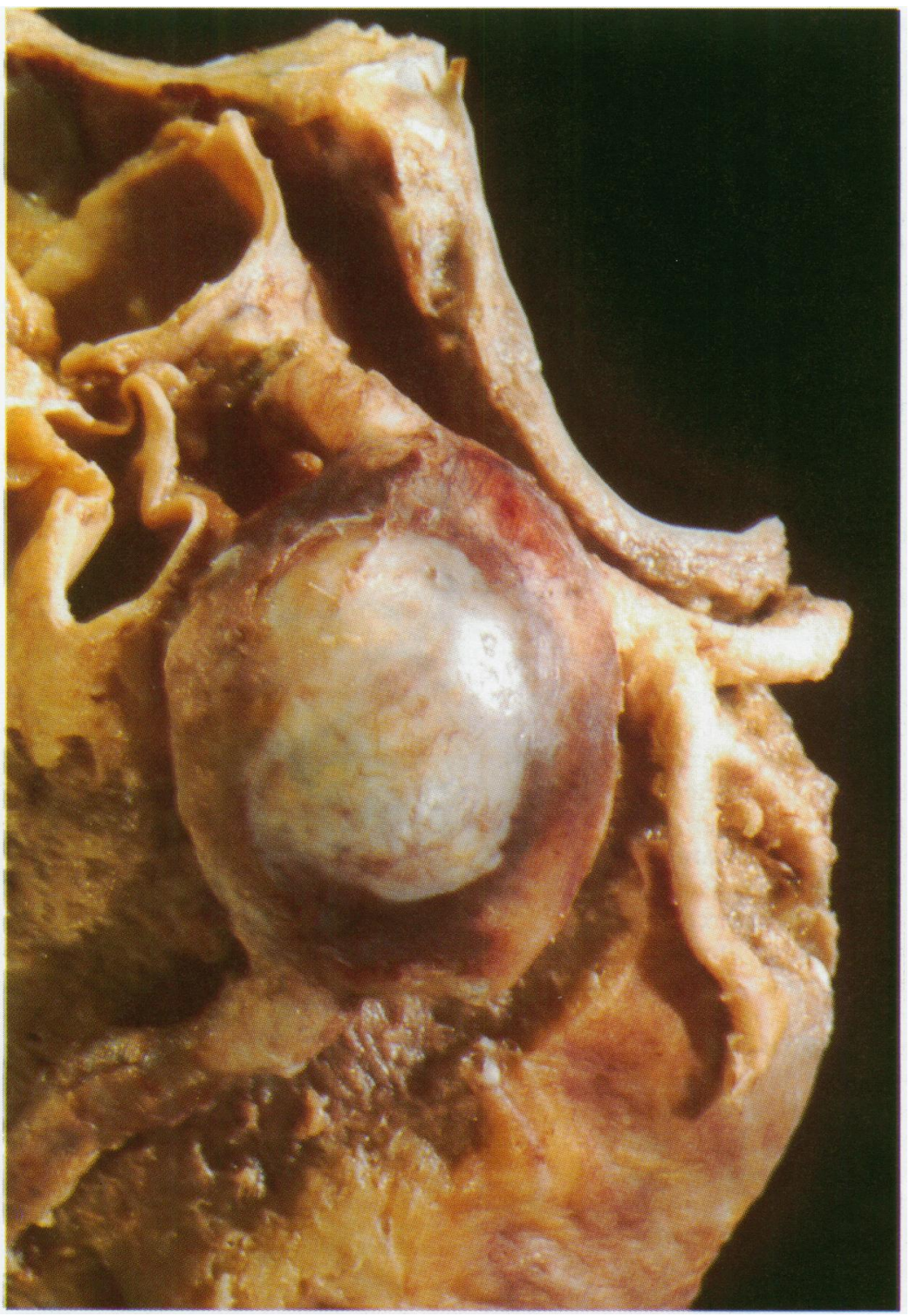

A 51 year old male with congestive heart failure (NYHA class II-III) presented with rapidly progressive dyspnoea two days after the onset of angina pectoris. On clinical examination he was in cardiogenic shock. ECG showed a subacute anterior myocardial infarction. Chest radiographs revealed an enlarged heart and a cardiogenic pulmonary oedema. Transoesophageal echocardiography showed dilatation of all cardiac cavities, an akinetic anterior wall and apex, a decreased left ventricular ejection fraction, moderate mitral valve regurgitation, and a $37 \mathrm{~mm}$ large aneurysm of the bifurcation of the left coronary artery. Coronary angiography revealed thrombotic occlusion of the left anterior descending artery at the level of the aneurysm, a normal circumflex artery, and a $90 \%$ stenosis of the right coronary artery. In spite of treatment with catecholamine, the low output state persisted and the patient died from congestive heart failure a few days after admission. Dissection of the coronary arteries showed a $3 \times 4 \mathrm{~cm}$ aneurysm of the bifurcation of the left coronary artery; the exact aetiology of this aneurysm remains unknown.

M MAGGIORINI J SCHNEIDER
R JENNI 